\title{
RTC, más que crimen organizado, cárteles o narcotráfico
}

\section{TCN, More than Organized Crime, Cartels, or Drug Trafficking}

\author{
Jorge Alejandro Vázquez Valdez* \\ (D) https://orcid.org/0000-0002-3527-2407 \\ Universidad Autónoma de Zacatecas, México \\ jorgevazmx55@gmail.com
}

Resumen: Los grupos de traficantes de droga son agentes predominantes en el escenario de hiperviolencia que lacera a México, y las palabras crimen organizado, cárteles o narcotráfico han sido utilizadas de manera imprecisa o arbitraria para definirlos, lo que propicia desaciertos conceptuales, desviaciones semánticas o viabilizar el intervencionismo y la criminalización. Pero en especial, esos conceptos resultan insuficientes para captar la evolución de dichos agentes, por lo que con la intención de redefinirlos como Redes Transnacionales de Criminalidad (RTC), se asume aquí una posición académica crítica a la postura dominante en materia de seguridad y se dimensiona su incidencia en los planos político, económico y social. El análisis da cuenta de los cambios en la relación agentes criminales-Estado; la división del trabajo al interior de las RTC; el engarce entre capitales lícitos-ilícitos; la inserción del capital criminal en el patrón de acumulación global y la ramificación de sus delitos.

* Doctorado en Estudios del Desarrollo, Universidad Autónoma de Zacatecas. Líneas de investigación: narcotráfico, derechos humanos, violencias sistémicas, emergentes y simbólicas.

cómo citar: Vázquez Valdez, J. A. (2021). RTC, más que crimen organizado, cárteles o narcotráfico. Secuencia (111), e1799. DoI: https://doi.org/10.18234/secuencia.v0i111.1799

cc Esta obra está protegida bajo una Licencia Creative Commons Atribución-NoComercial 4.0 Internacional. 
Palabras clave: redes transnacionales de criminalidad; narcotráfico; cárteles; crimen organizado.

Abstract: Drug trafficking groups are the main agents in the scenario of hyperviolence that plagues Mexico. The words "organized crime", "cartels" and "drug trafficking" have been used in an imprecise or arbitrary way to define them, which leads to conceptual errors and semantic deviations or makes interventionism and criminalization feasible. Above all, these concepts fail to capture the evolution of these agents. To redefine them as Transnational Crime Networks (TCN), an academic position critical of the dominant position on security matters is assumed here and their incidence is measured at the political, economic, and social levels. The analysis describes the changes in the relationship between criminal agents and the state; the division of labor within TCNs; the link between licit and illicit capital; the insertion of criminal capital in the global accumulation pattern and the consequences of their crimes.

Keywords: transnational crime networks; drug trafficking; cartels; organized crime.

Recibido: 17 de octubre de 2019 Aceptado: 12 de julio de 2020

Publicado: 27 de julio de 2021

\section{INTRODUCCIÓN}

Dese a que los grandes grupos de traficantes de drogas que operan en Mé1 xico han sido referidos de manera prácticamente ininterrumpida desde el inicio de la "guerra contra el narcotráfico", existe en torno a ellos una imprecisión conceptual que lo mismo conduce a organismos internacionales, medios de comunicación, académicos y autoridades locales a denominarlos "cárteles", "narcotraficantes" o "crimen organizado" de manera arbitraria o como si fueran sinónimos. Se trata de un fenómeno lingüístico en su rama semántica que se ha extendido en México principalmente en los últimos doce años, y más allá de los desaciertos en términos de definición que ello puede generar, la imprecisión guarda en sus entretelones lineamientos en materia 
de seguridad congruentes con esquemas políticos hegemónicos (organismos internacionales y naciones centrales); criterios editoriales que soslayan la precisión conceptual, o bien se inclinan por el sensacionalismo y los titulares vistosos (medios de comunicación y prensa); simplificaciones del término para encuadrarlo en un esquema punitivo-prohibicionista (gobiernos centrales y periféricos); sobredimensionamiento de los grandes grupos de traficantes de droga (narrativa del narco).

Con lo anterior no se afirma que "cárteles", "narcotraficantes" o "crimen organizado" no posean relevancia o autonomía conceptual, pero sí se sostiene que, además de los desvíos semánticos que existen actualmente en torno a ellos, son insuficientes para definir el nuevo perfil de los grandes grupos de traficantes de droga mexicanos. Esto representa un problema a resolver en este escrito con la intención de dimensionar las características de estos agentes criminales, por lo que se propone considerarlos Redes Transnacionales de Criminalidad (RTC), concepto que da cuenta de sus nuevas formas de articulación, su proyección y tipos de actividad que maximizan sus ganancias. Para desarrollar el concepto de RTC se determinan los criterios y umbrales sobre la definición de crimen organizado, los componentes económicos que deben cubrir los llamados cárteles de la droga, y la criminalización que de facto se puede desatar hacia individuos e incluso naciones.

De igual forma, como parte del método se expone la evolución que los grandes grupos de traficantes de droga mexicanos han tenido en los últimos años, evolución que contrasta con la simplificación que las autoridades han hecho de estos grupos criminales e implica un cambio significativo en sus relaciones con el Estado. Ellas se remontan al siglo xx y reflejan vínculos que los mantenían subordinados con las autoridades federales; sus configuraciones internas, las cuales han pasado de la lógica piramidal a una más efectiva y horizontal, como es el esquema tipo red con sus áreas de especialización, nodos que coordinan y supervisan actividades, y su capacidad de involucrar las esferas política y económica; su perfil paramilitar, que ha dotado de eficiencia pero también hiperviolencia sus actividades ilícitas; sus formas de explotación de individuos, las cuales no son idénticas ${ }^{1}$ a las formas de explotación ejercidas en el capitalismo tradicional en tanto la inequidad no radica esen-

${ }^{1}$ Las formas tradicionales de alargamiento de la jornada laboral o intensificación de las actividades pueden estar presentes en la explotación ejercida por el narco, pero cabe la distinción de que pueden realizarse de manera voluntaria o forzada. 
cialmente en la baja retribución por la apropiación desmesurada de trabajo vivo, sino en la baja remuneración a pesar del riesgo de perder la vida o ser detenido; la ramificación de sus nichos de ganancia, lo que ha robustecido su economía criminal, pero también ha lacerado progresivamente a la sociedad en tanto incluye delitos -generalmente violentos- que atentan contra la vida digna y, por tanto, el desarrollo humano. Su proyección internacional implica la posibilidad de aumentar su excedente y articularse con mafias para extender un tinglado criminal que sostiene el negocio de las drogas ilícitas, pero también otros muy lucrativos a escala en México y en el ámbito internacional, como la trata de personas. La incidencia de las RTC en el plano internacional va más allá de que tengan presencia en otros países, incrementen sus ganancias de forma brutal o signifiquen una amenaza transnacional que demande el trabajo conjunto entre naciones para frenarlos. Sus vínculos con el sistema financiero para el blanqueo de dinero reflejan la compatibilidad entre capitales lícitos e ilícitos en primera instancia, pero también que el acotamiento a las RTC no se ejerza en igual proporción hacia el sistema financiero que funge como su cómplice en el lavado de dinero, producto del trasiego de estupefacientes. En el mismo sentido, cabe mencionar que las ganancias derivadas de delitos, como la trata de personas, también podrían estar siendo ingresadas al sistema financiero para su blanqueo, lo que representa una implicación más delicada de parte de los bancos en tanto que estarían tomando parte -como blanqueadores de ganancia- en los ilícitos que atentan contra la vida y otros delitos que articulan la ramificación de sus actividades. En un nivel mayor, se debe considerar que la criminalización que se hace de los individuos integrantes de los eslabones más débiles de la cadena de valor de la droga (campesinos, transportistas y distribuidores) alcanza a los propios países periféricos, en tanto que son objeto de una mayor criminalización derivada de un andamiaje en materia de seguridad que privilegia intereses hegemónicos, lo cual se viabiliza mediante la llamada "Guerra contra las drogas".

\section{CRIMEN ORGANIZADO Y CÁRTELES, ENTRE LA IMPRECISIÓN CONCEPTUAL Y EL ALINEAMIENTO A POLÍTICAS HEGEMÓNICAS}

Sobre el concepto de crimen organizado, históricamente no se ha logrado establecer una definición común (Fuerte, 2016, p. 11), y a pesar de que es de uso co- 
tidiano en el debate público y la literatura académica, es un constructo contradictorio y difuso (Von Lampe, 2016, p. 33). A ello se suma el que no exista una legislación internacional vinculante, sino sólo algunos acuerdos para incluir determinadas reglas en el derecho de cada Estado-nación, y prestar colaboración en la lucha contra el crimen organizado (Contreras, 2012, p. 10), lo cual parte del principio de soberanía y autodeterminación de los pueblos. No obstante, su empleo en nuestros días es "esencialmente una invención de Estados Unidos" (Von Lampe, 2016, p. 15), lo que da cuenta de los usos y orientaciones que al concepto se le pueden dar, además de que de ello depende cómo se enmarcan las leyes, cómo se llevan a cabo las investigaciones y los enjuiciamientos, y cómo funciona la asistencia legal binacional (Finckenauer, 2005, p. 68).

La definición más extendida sobre el crimen organizado es la de Naciones Unidas, y tanto para referir a un "grupo criminal organizado" como para abordar el carácter transnacional de alguno de ellos, no se puede soslayar la Convención de las Naciones Unidas contra el Crimen Organizado Transnacional (UNTOC, por sus siglas en inglés). De acuerdo con su Artículo 2(a), el crimen organizado puede definirse como "un grupo de tres o más personas que no fue formado de manera aleatoria; que ha existido por un periodo de tiempo, actuando de manera premeditada con el objetivo de cometer un delito punible con, al menos, cuatro años de encarcelamiento, y con el fin de obtener, directa o indirectamente, un beneficio financiero o material" (UNODC, 2019).

Componen dicho concepto los criterios de umbral numérico, que alude a la pertenencia a un grupo delictivo de tres o más miembros; criterio de concertación de las actividades delictivas organizadas, según los tipos de delitos contemplados por Naciones Unidas, y los criterios lucrativo y criterio de transnacionalidad (Escribano, 2009, p. 29). ${ }^{2}$ Dichos criterios han resultado ejes para identificar y dimensionar a los grupos criminales que operan en diversas latitudes, y pese a que puede llegar a haber discrepancias (por razones como las metodologías empleadas) entre actores como Estados Unidos y la propia Naciones Unidas con respecto de actividades delictivas como la pro-

${ }^{2}$ La delincuencia organizada es un concepto muy cercano a esta definición. De acuerdo con la Convención de las Naciones Unidas contra la Delincuencia Organizada Transnacional y sus Protocolos, por "grupo delictivo organizado" se entenderá un grupo estructurado de tres o más personas que exista durante cierto tiempo y que actúe concertadamente con el propósito de cometer uno o más delitos graves o delitos tipificados con arreglo a la presente Convención con miras a obtener, directa o indirectamente, un beneficio económico u otro beneficio de orden material. 
ducción y el comercio de drogas, ambos siguen siendo las principales fuentes de información cuantitativa. El primero mediante el Departamento de Estado de Estados Unidos, concretamente en su Informe Anual sobre la Estrategia Internacional de Control de Narcóticos (INCSR, por sus siglas en inglés). El segundo a través de la Oficina de la ONU contra las Drogas y el Crimen (UNODC) (González, 2014, p. 20).

Para 2012, la Oficina de Naciones Unidas contra la Droga y el Crimen señaló que las redes criminales habían evolucionado y se convirtieron en empresas multinacionales y multirregionales que generan miles de millones de dólares. De acuerdo con la UNODC, las actividades del crimen organizado superaban ganancias anuales de dos billones de dólares, equivalente a 3.6\% de todo lo que produce y consume el planeta en un año (Naciones Unidas, 2012). De igual forma, es preciso señalar la ramificación de las actividades ilícitas. Al respecto se puede citar al Global Financial Integrity (GFI), que desde 2011 consideraba doce actividades ilegales con altas ganancias, y para ese periodo figuran el narcotráfico, con ganancias de 320000 millones de dólares anuales; la falsificación, con 250000 millones de dólares anuales; el tráfico humano, con 31600 millones de dólares anuales; el tráfico ilegal de petróleo, con 10800 millones de dólares anuales, y el tráfico de vida salvaje, con 10000 millones de dólares anuales (Justo, 2016). Aunque es claro que las actividades ilícitas trascienden el trasiego de estupefacientes, su complejidad no se agota ahí, sino que "El crimen organizado y en especial el narcotráfico -en tanto su columna vertebral- constituyen una densa red que involucra distintos niveles del gobierno, de las fuerzas de seguridad, de los partidos políticos y del empresariado en el ámbito nacional, así como a poderosos grupos públicos y privados en el ámbito internacional" (Calveiro, 2012, p. 208). Con base en esta red, es que las RTC mexicanas han tomado parte en los delitos de esa ramificación, en particular el tráfico ilegal de petróleo, y el tráfico humano y de vida salvaje.

Pese a dicha cuantificación, y a que los criterios referidos han servido como parámetro para las naciones que los han seguido respecto de los grupos delictivos, lo cierto es que el concepto de crimen organizado resulta sumamente limitado y problemático (Astorga, 2014); tiene una dimensión normativa y operativa que ha generado políticas y legislaciones, y tiende a homogeneizar dentro de un mismo concepto una serie de fenómenos criminales que son muy diversos (Argueta, 2014). De estas últimas dos consideraciones se desprende que dicha normatividad y operatividad pueden orientarse a ser 
rieles de proyectos hegemónicos en materia de seguridad como el estadunidense, o a que el esquema punitivo y la seguridad privada -en su rama de servicios carcelarios, por ejemplo-, criminalizan de facto a los actores más vulnerables de los grupos delictivos, particularmente pobres, campesinos encomendados al cultivo de enervantes, a niños, países o incluso regiones. ${ }^{3}$ Con la llegada de la cocaína, y al pasar Estados Unidos a ser uno de los mayores espacios de consumo a nivel internacional, la medida política de Richard Nixon de instaurar una "guerra contra las drogas" hilvanó el discurso de mano dura y el promover el uso de estupefacientes como el "enemigo público número uno". Dicha medida también sirvió de plataforma para que Estados Unidos redoblara su injerencia en América Latina a partir de alinear el problema del consumo de drogas a la noción estadunidense de seguridad nacional.

Dos aspectos críticos sobre ello son la certificación de la que países como Colombia, Perú y Bolivia han sido objeto a partir del apoyo y asesoría que Estados Unidos les ha brindado en materia de seguridad, y en segundo término, el hecho de que la "guerra contra las drogas" comenzaba a ser una nueva coartada (en conjunto con la guerra contra el terrorismo) para legitimar las operaciones militares, bases e intervencionismo estadunidense en el exterior (González, 2014, pp. 52-54). Dicha posición de mano dura; la simplificación del fenómeno de la producción, distribución y consumo de droga, así como el intervencionismo en el exterior, embona con el enfoque del establishment estadunidense en torno a dicho fenómeno, en particular con uno de sus dos ejes, el del conservadurismo (Benito, 2015, p. 247), y refleja que América Latina es un escenario crucial de la guerra contra las drogas por dos razones: su papel clave en la producción y comercio mundial de cocaína, y la cercanía geográfica y política con Estados Unidos, el principal mercado consumidor, a partir de lo que ese país ha promovido un enfoque basado en una imposición agresiva de la ley y la encarcelación como modelo para la región (González, 2014, p. 72), además de que ha resultado una coartada eficiente para el "financiamiento de operaciones encubiertas de la ciA -apoyo a 'los contras' nicaragüenses y a la resistencia a la ocupación soviética en Afganistán durante los años ochenta; y posteriormente, para sus programas ocultos o SAP-" (Calveiro, 2012, p. 167).

${ }^{3}$ Por razones de análisis estos dos argumentos se profundizan más adelante en el texto, pero es importante referirlos en este punto para dar cuenta de la contraparte a la postura dominante en torno al concepto de crimen organizado. 
Los saldos a partir de las prescripciones de Estados Unidos han fomentado la militarización de la seguridad pública con saldos más negativos que positivos, como refiere el Latinobarómetro, pues sus estudios reflejan que la ciudadanía recela más la eficiencia de la capacidad del poder público para frenar la delincuencia en los países donde se ha militarizado la seguridad ciudadana (Castillo, Ríos y Peccis, 2015, p. 35). La persistencia a mantener dicho esquema es congruente con el hecho de que "EE UU ha ido proyectando sus propias percepciones de (in)seguridad y las necesidades estratégicas derivadas de estas, como acciones complementarias al rol que ha ido ocupando el país en el escenario internacional a lo largo de su historia" (Benito, 2015, pp. 245 y 246). Es decir, el discurso en torno al fenómeno de producción y tráfico de drogas ha dependido de la agenda en materia de seguridad estadunidense, y no necesariamente de un trabajo conjunto entre los países que padecen y se ocupan de dicho fenómeno. De este modo, la noción de crimen organizado resulta una coartada para perpetuar el intervencionismo tras la guerra fría; justifica la asesoría a otros países en materia de seguridad; viabiliza el uso de las fuerzas armadas para las tareas de seguridad pública, e impone una percepción maniquea en la que Estados Unidos se asume y promueve como el agente que detenta el poder último, tanto en despliegue de fuerza mediante sus bases militares, como en el uso de la "vara" para medir a países afines o contrarios a su proyecto hegemónico.

Además de crimen organizado, el término cárteles es comúnmente usado para referirse a los traficantes de droga de alto nivel, y su uso se ha extendido en México en el marco de la guerra contra el narcotráfico. No obstante, hay que hacer hincapié en que existe una discrepancia implícita sobre lo adecuado que resulta la palabra para definir a los traficantes de drogas ilícitas. Por un lado, se puede referir la posición de los académicos de la Universidad Autónoma de Madrid, Luis de la Corte y Andrea Giménez-Salinas, quienes sostienen que el término proviene del ámbito económico, y se refiere a los acuerdos formales que establecen empresas de un mismo sector con la intención de reducir o eliminar la competencia de un determinado mercado. Las empresas que participan de un cártel fijan los precios de los productos que comercializan, limitan su oferta y dividen el mercado de esos productos para compartir beneficios en perjuicio de los consumidores (Corte y Giménez-Salinas, 2010, p. 137). Por su parte, Luis Astorga (2015, pp. 181-182) no cuestiona que el término sea funcional en el contexto económico, pero sí argumenta en contra de que se use como sinónimo de los traficantes de droga. Su señala- 
miento es que no existe un "cártel" en tanto persisten las disputas violentas entre los diversos grupos que se encuentran activos; dichos grupos no se han unido de forma voluntaria y permanente para dominar la cadena de valor de las mercancías ilegales que trafican; el término ha sido usado de forma arbitraria y ello ha conducido a una imposición de sentido, ya sea por desconocimiento, por la carga mitológica que los grupos criminales pretenden ostentar, o por propósitos políticos -como el de estigmatizar a un país determinado. ${ }^{4}$

Luis de la Corte y Andrea Giménez-Salinas (2010, p. 137) señalan que la palabra cártel comenzó a emplearse con los principales grupos de traficantes de droga colombianos, que en esa década habrían establecido límites en la cantidad de cocaína producida en todo el hemisferio occidental y a que fijaron precios de ese producto a escala internacional. Luis Astorga (2015, p. 198), por su parte, sostiene que fueron los agentes de la DEA y los fiscales de Florida quienes comenzaron a designar a los grupos de traficantes colombianos con la palabra cártel, pero ello tendría como trasfondo la etiqueta y la estigmatización. La falta de precisión conceptual en altos niveles gubernamentales sobre la palabra cártel es expuesta por el propio Astorga (2015, pp. 85-86), al señalar cómo el expresidente Felipe Calderón llegó a afirmar que México pasó de un modelo de narcotráfico tradicional, orientado principalmente al mercado estadunidense, a un "modelo de narcomenudeo". La referencia de Calderón simplificó la transformación del fenómeno de los traficantes de droga mexicanos, en razón de que ese supuesto cambio no consideraba aspectos nodales como el de la relación con la esfera política. Inclusive, Calderón equiparó su noción de cárteles con la de narcomenudistas, lo cual es complicado de afirmar; primero, porque como ya se señaló, los grupos de traficantes de droga mexicanos no cumplen con la definición de los cárteles (particularmente en su componente operativo, económico y de control de mercados); y, en segundo lugar, porque los narcomenudistas son, por definición, grupos delictivos de menor calado que están enfocados en un comercio clandestino a baja escala. Cabe señalar en este punto que además de los ecos de imprecisión conceptual que del discurso del ejecutivo federal se pueden derivar, está el riesgo de que ello tenga influencia en el terreno legislativo y judicial, y que ello termine por ser una vuelta de tuerca en el esquema punitivo que criminaliza por igual

${ }^{4}$ En este punto debe considerarse también a Mabel González, quien afirma que los grupos criminales no son cárteles en tanto no controlan la totalidad del mercado, la cadena de producción, ni tienen la capacidad de fijar precios (González, 2014, p. 16). 
a delincuentes de gran calado y a individuos con una participación mucho menor en el ilícito del tráfico de estupefacientes. ${ }^{5}$

La expansión que Luis de la Corte y Andrea Giménez-Salinas señalan sobre los grupos de traficantes colombianos en la década de los ochenta es legítima, y si a partir de ello los grupos criminales de Cali y Medellín no pueden considerarse como cárteles, ${ }^{6}$ al menos sí se desenvolvieron como grupos criminales con tendencia al monopolio. De igual manera cabe señalar que el fenómeno no ha sido exclusivo de Colombia, y alcanza a México, sólo que en momentos y casos muy específicos. Al respecto se puede referir al llamado "Cártel de Guadalajara" (o Federación de Traficantes de Droga) que sí presentó una estructura que "operaba con tendencia al monopolio, y con otros grupos que originalmente provenían de Sinaloa controlando y operando el comercio y sus rutas a lo largo de todo el país" (González, 2014, pp. 127-128). Luego de esa concentración de poder y su correspondiente tendencia al monopolio la diseminación fue la constante, y dio paso al escenario actual donde "Lo que hay son simples organizaciones criminales de diferente tamaño y capacidad, con mayor o menor diversificación de actividades delictivas y posibilidades distintas de ejercer violencia al interior de sus organizaciones, contra sus competidores, las fuerzas de seguridad del Estado y la sociedad" (Astorga, 2015, p. 181).

${ }^{5}$ A este respecto, cabe visibilizar el escenario mexicano donde han confluido el alineamiento progresivo a las políticas de "lucha contra las drogas" que inició en los albores del siglo xx; reformas como la del Código Penal de 1940 o 1978 (Hernández, 2010, p. 61) que buscaron limitar el trasiego y el consumo, y medidas como la Cruzada nacional contra el crimen, de 1998, la cual tuvo como eje la tolerancia cero y se orientó en contra de las clases populares y abandonadas por el Estado caritativo (Wacquant, 2004, p. 40). El correlato de esto está en hechos como el de que entre 1992 y 2003, la población carcelaria en México aumentó a un ritmo sin precedentes; uno de los factores de ello fueron las reformas a los códigos que endurecieron las penas, y en general los centros penitenciarios no se han ido llenando por los delincuentes que han cometido los delitos más peligrosos, sino los más pobres (Azaola y Bergman, 2003, pp. 5, 6, 20). Es decir, el aumento en los delitos y las penas han entroncado con una criminalización focalizada en la pobreza, la cual es base del "ejército" de reserva de las RTC. En los años posteriores a lo anterior, el narco fue posícionado como el antagónico principal en el discurso maniqueo, lo cual se acentuó en el Eje 1, "Estado de derecho y seguridad" del Plan Nacional de Desarrollo (PND) 2007-2012. A raíz de ello, miles de personas han sido encarceladas por delitos contra la salud -en especial pobres-, cuando en contraste, durante las presidencias de Enrique Peña Nieto y Felipe Calderón, de 233 objetivos criminales prioritarios, sólo dos obtuvieron sentencia irrevocable (Redacción Expansión, 2019).

${ }^{6}$ En Colombia la palabra no es grave (cártel), sino aguda (cartel), pero para el presente texto se usa de la primera forma debido a que es la de uso generalizado en el país de origen del texto. 
Además de las dimensiones económica y política que deben considerarse en torno a la palabra cártel, también cabe mencionar que la palabra ha sido utilizada bajo los propios criterios de la prensa, los cuales no necesariamente están unificados con los de las autoridades. Por ejemplo, para 2014 la Procuraduría General de la República (PGR) sostenía que en el país había "9 cárteles del narco" (Redacción Aristegui Noticias, 2014), y para el inicio de la administración federal encabezada por Andrés Manuel López Obrador, en el país operaban "seis cárteles", ${ }^{7}$ según las secretarías de Gobernación (SEGOB), Secretaría de la Defensa Nacional (SeDena) y la Procuraduría General de la República (PGR). Desde el inicio de la "Guerra contra el narco" el número de esos grupos delictivos no se ha mantenido fijo, pero es posible aseverar que, al menos de acuerdo con los organismos oficiales, ese número ha rondado los diez "cárteles".

No obstante, hay variaciones. Por ejemplo, Contralínea publicó en 2013 que en el país hay "89 cárteles que arrasan México" (Camacho, 2013); Televisa, por su parte, divulgó en 2018: "Aumenta guerra narco capitalina; 11 cárteles operan en la CDMX" (López de Rivera Hinojosa, 2018), lo que significaría que o prácticamente todos los grandes grupos de traficantes de droga operan en la Ciudad de México, o que hay once de esos grupos radicados sólo en la capital del país. Los medios de comunicación (algunos sensacionalistas y enfocados en la "nota roja") son fuentes que también suelen referir a los llamados cárteles, en un ejercicio editorial que intermitentemente los enaltece, los sobredimensiona o incluso genera "estereotipos" (Fuerte, 2016, p. 12), sólo que en función de la atracción de lectores o televidentes, y no del apego a la seriedad periodística o a la precisión conceptual.

\section{DEL TRASIEGO DE DROGA A LA RAMIFICACIÓN DE LOS DELITOS}

De acuerdo con la Real Academia Española (2019), el narcotráfico se define como: "1. m. Comercio de drogas tóxicas a gran escala", ${ }^{8}$ definición que no es

${ }^{7}$ M. Muedano, "Dominan 80 células del narco en México; operan seis cárteles", Excélsior, 26 de noviembre de 2018. Recuperado de https://www.excelsior.com.mx/nacional/ dominan-80-celulas-del-narco-en-mexico-operan-seis-carteles/1280724

${ }^{8}$ De acuerdo con la RAE, el narcotraficante sería el individuo que trafica con estupefacientes, por lo que esta categoría no alcanza para definir a quiénes, en las RTC, realizan actividades adicionales al tráfico de drogas. 
desacertada si se considera que en términos estrictos, se trata del traslado de estupefacientes de un lugar a otro. No obstante, la propia evolución de esos grupos criminales hace que la noción del trasiego de droga sea insuficiente para definir sus nuevas características. Cabe aclarar que esas características pueden variar entre los grupos criminales, en especial si son de diversos países, por lo que a continuación se hace énfasis sólo en los grupos de traficantes de droga mexicanos. Seis características son las que al respecto deben ser tomadas en consideración: su autonomía relativa en el marco de su relación histórica con el Estado, su nueva configuración tipo red, el llenado de vacíos de Estado, la facción paramilitar, la ramificación de sus delitos y el tipo de explotación en que incurren.

Hay un cambio con respecto a la relación tradicional que ha existido entre traficantes de droga mexicanos y el Estado (Emerich, 2015), relación que en las últimas décadas se ha modificado de forma más acelerada y cualitativa (Astorga, 2015, p. 14). Ese vínculo se remonta a las primeras décadas del siglo xx, caracterizándose por la subordinación del tráfico de drogas ilícitas a la esfera política, y esa dinámica se mantuvo hasta que se dio paso a una "autonomía relativa" (Astorga, 2012, p. 162) del narcotráfico, desde la que transitaron de un esquema de organización piramidal, al de tipo red (González, 2014). Cabe señalar que la responsabilidad del Estado en su relación con los grandes traficantes de droga generalmente es soslayada en la visión maniquea, pues esta parte del supuesto de que el Estado es objeto de penetración por parte de los grupos criminales. Congruente con esa dinámica está la perspectiva de la "reconfiguración cooptada del Estado" basada en el poderío de los grupos criminales (Garay y Salcedo, 2012); o la de la justificación de la política punitiva en torno a la guerra contra el narco, bajo el argumento de que la administración presidencial calderonista no tenía otra opción, al tiempo que se justificaba la asesoría por parte de Estados Unidos en materia de seguridad (Chabat, 2010).

Ahora bien, hay un consenso implícito -no generalizado, pero sí extendido- sobre los cambios en la relación entre los traficantes de droga y el Estado, y ese consenso se ha acentuado en el marco de la guerra contra el narcotráfico debido a la preponderancia que aquellos tienen en el "uso de la violencia para lograr sus objetivos” (Fuerte, 2016, p. 14). Ese consenso alcanza desde el ciudadano común hasta la prensa y finalmente a los estudiosos del tema, pero el punto en el que el consenso no está tan extendido es en el grado de relación que ambos han tenido, y en las causas por las que esa relación se ha modificado. Al respecto hay que señalar la pérdida de legitimidad del mando político 
mexicano ante la crisis del Estado, concretamente la vulneración de los pilares de la constitución estatal (Roux, 2011). Esta pérdida de legitimidad abrió una ventana de oportunidad para los traficantes de droga, pues la correlación de fuerzas cambió tanto por el deterioro del pacto político-social, como por el hecho de que en algunos casos dejaron de estar subordinados.

La relación esfera política-traficantes de drogas ilícitas en México conjuga dos elementos: a) desde la formación del campo del tráfico de drogas en México este se vio supeditado al campo político (en especial a partir de la segunda década del siglo xx), y así fue durante décadas, hasta que se dio un resquebrajamiento progresivo del sistema político posrevolucionario basado en el presidencialismo y en el partido de Estado; el avance de la oposición política en el Congreso y en los gobiernos estatales, y finalmente la alternancia en el poder, que implicó el desplazamiento del PRI en el poder ejecutivo federal (Astorga, 2012, pp. 161-162); y, b) el gobierno mexicano ha generado un discurso cargado de juicios de valor que limita contemplar otras experiencias o momentos históricos que permitieran tener mayor perspectiva para superar la visión maniquea del "combate al narco".

Desde los años veinte del siglo pasado el gobierno empezó a promover la prohibición y cultivo de mariguana argumentando motivos morales, y al mismo tiempo empiezan a surgir las acusaciones de vínculos entre funcionarios de alto nivel y el tráfico de drogas. En los años cuarenta empiezan a ser cada vez más comunes en el discurso político las palabras lucha, combate, cruzada, guerra, campaña, de corte militar para referirse a la acción estatal contra el cultivo y tráfico de drogas (Astorga, 2012, pp. 31 y 63), lo que bien puede considerarse el preámbulo a la idea de Carlos Montemayor sobre la perspectiva de un Estado que se maneja por la lógica del combate, y no por la premisa de comprender y atender un fenómeno social. Es decir, se trata de una violencia de Estado que se soporta en la coartada del "combate al crimen organizado", y deviene en la posibilidad de criminalizar la protesta social; ejercer la desaparición forzada -sello de la guerra sucia de los años setenta del siglo $\mathrm{xx}-$, y las acciones represivas contra la guerrilla mexicana y contra los defensores de los derechos humanos y sociales de comunidades indígenas (Montemayor, 2010, p. 235).

Como parte de los aspectos evolutivos más destacados de los grandes grupos de traficantes de droga mexicanos, está el del paso de su organización jerárquica a la organización tipo red, la cual implica vínculos que conectan a dos o más personas directa o indirectamente, y dichas conexiones entre los 
criminales no son necesariamente fáciles de observar (Von Lampe, 2016, pp. 106-107). La organización tipo red implica para esos grupos criminales una lógica operativa mucho más eficiente y cuyo modelo no se basa en grandes organizaciones jerárquicas sino en diversos grupos descentralizados; han adoptado características de la red 2.0, con eslabones que pueden conectarse o desconectarse en cualquier momento; presentan una descentralización de la información y el conocimiento, y un poder que se basa más en las conexiones que en la capacidad de mando (González, 2014, p. 16).

La descentralización es parte del cambio de organización piramidal, e implica una mayor complejidad en su estructura:

La evolución del crimen organizado en Colombia y México, en sus estructuras y dinámicas internas, confirma las teorías sobre aprendizaje y cambio organizativo (tanto en lo que se refiere a los grupos como al mercado en su conjunto). En una mirada hacia dentro de los grupos, se observa que son altamente complejos y contienen varios niveles que pueden visualizarse como círculos concéntricos: nodos centrales coordinando y supervisando el negocio; círculos de segundo nivel, especializados en ciertas tareas y/o territorios, y círculos más externos, de personas y grupos empleados ocasionalmente para tenerlas externalizadas (González, 2014, pp. 166-167).

La evolución referida ha resultado beneficiosa para los grandes grupos de traficantes de droga mexicanos, primero porque ello ha desembocado en la base para consolidar o expandir el trasiego de estupefacientes a escala transnacional, y después porque esa evolución también ha sido la base para poder ramificar sus actividades ilícitas -principalmente en México-y ejercer un tipo de explotación más agresiva y expedita sobre quienes componen los eslabones más débiles de la cadena de valor de la droga.

Desde la perspectiva de Estado hay que señalar que existe una "interacción entre los Estados y los actores criminales, incluso cuando el Estado no está corrompido o aliado con grupos criminales. Los gobiernos y las organizaciones criminales emplean la evasión y la corrupción para coexistir en relaciones de equilibrio en las cuales cada uno se ajusta continuamente a la evolución percibida del otro" (Bailey y Taylor, 2009, p. 8). Pero cuando los Estados son débiles, corruptos o ineficaces, se crea un vacío de poder que es llenado por la mafia, quien asume las funciones que el gobierno es incapaz de proveer debido a que no posee el monopolio de la violencia (Fuerte, 2016, 
p. 12). Además, los altos niveles en la tasa de asesinatos, secuestros y venalidad de la policía, propios del estado fallido mexicano, exacerban la velocidad del flujo migratorio hacia el norte (Grayson, 2017, p. 15), y propician fenómenos como el de inhibición de la participación electoral en áreas afectadas por altos niveles de violencia criminal (Trelles y Carreras, 2012, p. 99). Por los vacíos de Estado, "el crimen organizado" aprovecha la vulnerabilidad para conseguir protección comunitaria (Buscaglia, 2013).

En un nivel mayor se puede asimilar dicho fenómeno desde dos vertientes, la económica y la de que esos vacíos de Estado se encuentran asociados a la falta de legitimidad del mando político (referida previamente desde las consideraciones de Rhina Roux), lo que es un punto en el que también se puede incluir a Jaime Osorio, pues la falta de legitimidad del Estado se refuerza con su falta de inacción o incompetencia para satisfacer las necesidades de la población, con los privilegios que brinda a los grupos dominantes, y con los diversos fraudes electorales, lo que deviene en un "enorme vacío de dirección existente en la sociedad. El crimen organizado constituye una respuesta a ese vacío y encuentra condiciones políticas y económicas favorables para desarrollarse" (Osorio, 2011, p. 60), lo que se acentúa una vez que logran incidir el plano político. El consejero presidente del Instituto Nacional Electoral (INE), Lorenzo Córdova Vianello, ha asegurado que no hay dinero del narcotráfico y del crimen organizado en las campañas electorales en México, ${ }^{9}$ pero su posición contrasta con otras afirmaciones. Sobre eso se puede mencionar la de Miroslava Breach, periodista asesinada en el estado de Chihuahua en 2017, luego de reportar la infiltración del crimen organizado en la política, en concreto con la imposición de candidaturas (Redacción Animal Político, 2017); las acusaciones mutuas entre los expresidentes del Partido Revolucionario Institucional (PRI) y el Partido Acción Nacional (PAN) por ligas con el narcotráfico (Redacción El País, 2016), o la del Senado de la República, el cual ha advertido que hasta $80 \%$ de los alcaldes del país se encuentran vinculados al narcotráfico (Ravelo, 2018).

La relación entre la esfera política y los traficantes de droga en México comienza con la subordinación de los segundos hacia la primera, relación que se ha venido reconfigurando en los últimos años primordialmente por la tran-

9 V. Ballinas y A. Becerril, "No hay dinero del narco en campañas: Córdova", La Jornada, 15 de noviembre de 2018. Recuperado de https://www.jornada.com.mx/2018/11/15/ politica/012n2pol?partner=rss 
sición política a escala federal, estatal y municipal. ${ }^{10}$ Una vez que los grupos criminales se imponen, los políticos producto de dichas sociedades se prevé defiendan ante el Estado y la sociedad la preservación de las transformaciones ocurridas por la inyección del capital de las drogas (Duncan, 2014, pp. 64-65). La otra vertiente a considerar es la económica, sólo que no nada más por representar la solvencia individual o familiar, sino por ser un factor estructural que puede llegar a asociarse con el fenómeno de la violencia:

Ciudades como Reynosa, Tijuana y Ciudad Juárez situadas en la frontera con los Estados Unidos, con grados de violencia rampante, se han distinguido por ser territorios de empresas maquiladoras que han sido incapaces de promover procesos de industrialización endógenos y han continuado siendo una especie de espacios geográficos residuales fronterizos. Ante la ausencia de una industrialización que provocara la mejora sustancial de sus economías locales y sus lazos sociales, la violencia se ha convertido en un elemento estructural. Debemos recordar que el $90 \%$ de las drogas pasan por varias de estas ciudades y eso explica su importancia estratégica para el crimen organizado y los gobiernos locales en todas sus jerarquías que participan en dichas actividades (Villafañe, 2015).

En el marco del modelo de desarrollo neoliberal mexicano impulsado en el país por el PRI y continuado por el PAN a nivel federal durante los últimos años, las opciones para transitar hacia alternativas como la de una Industrialización por Sustitución de Importaciones (ISI) y otras opciones de desarrollo endógeno han quedado acotadas, y la vulnerabilidad social que de ello se desprende ha generado extensas capas sociales que son fácilmente cooptadas por los grupos criminales. Se trata de un fenómeno en el que las violencias sistémicas, hilvanadas por la exclusión social, la precarización del empleo o la falta del mismo, así como la inseguridad en materia de salud y educación se vinculan con la violencia desatada por los grupos criminales.

La cooptación forzada de ciudadanos por parte de los grupos criminales tampoco puede soslayarse, y esta se debe en buena parte a la necesidad de dichos grupos de satisfacer múltiples tareas a partir de la ramificación de sus actividades ilícitas y el perfil evolutivo previamente referido en este texto. Es decir, a la par del tráfico de estupefacientes han generado variadas fuentes de

10 "A este nivel hay menor control sobre los grupos criminales, en especial en los municipios descentralizados" (Contreras, 2013, p. 175). 
ganancia, las cuales han requerido no sólo de más personas para desarrollarlas, sino de perfiles específicos, tales como arquitectos, ingenieros, médicos, enfermeras, abogados, contadores, entre muchos otros que son cooptados incluso en las redes sociales (EFE, 2014). Se debe tener presente que muchas de estas personas laboran para el narco prácticamente en condiciones de esclavitud o bajo amenaza, pero también que los individuos que les prestan sus servicios no lo hacen bajo la gran contradicción económica entre el capital y el trabajo, sino entre la protección y el trabajo, ${ }^{11}$ es decir, la explotación es distinta entre el capitalismo legal y el narco, en tanto en la segunda "Se explota a los trabajadores en la medida en que sus ganancias obtenidas no compensan los riesgos asumidos" (Duncan, 2014, p. 39). Los eslabones más débiles de la cadena de valor de la droga, como son campesinos o distribuidores de bajo calado, son los que asumen riesgos mayores no sólo por la posibilidad de ser vinculados con los estupefacientes que manipulan directamente, sino por la imposibilidad de acceder a defensa legal de primer nivel (incluso a simples amparos), y en última instancia a que los beneficios económicos siempre serán menores que los de quienes componen los eslabones más fuertes. Cabe reiterar que en el ámbito de la relación que los grupos criminales mantienen con la sociedad, no todos los que se suman a esos grupos lo hacen de manera forzada.

La ramificación de las fuentes de ganancia de los grandes traficantes de droga incluye delitos que no son tan conocidos o analizados, como los de la tala y tráfico de maderas, el robo de combustible o el saqueo y explotación de mineral, por citar sólo tres ejemplos. La tala ilegal de bosques y selvas tropicales por parte de los llamados "cárteles de la droga" ha sido definida como una "narco-deforestación" que afecta no sólo a México, sino que se extiende hasta Honduras, Guatemala y Nicaragua a partir de la guerra contra el narcotráfico. La afectación a la fauna y la flora es sólo un efecto de ese desplazamiento de los grupos criminales hacia el sur de la frontera México-Guatemala, pues a ello se suma la especulación de tierras; la expulsión, asesinato o esclavización de indígenas; la inversión en ranchos de ganado para el lavado de dinero y la producción intensiva de aceite de palma (Redacción Sinembargo, 2014). En México, la tala ilegal comandada por caciques y perpetrada por hombres armados amenaza a los rarámuris en la sierra tarahumara (Mayorga, 2020).

${ }^{11}$ Cabe señalar que estas valoraciones no siempre aplican a todos los grupos del crimen organizado. 
Un negocio que les ha resultado sumamente rentable ha sido el del robo de combustible, pues se calcula que socava más de 1000 millones de dólares en ingresos anuales del Estado, lo que tiene como origen el que, entre 2011 y 2016, el número de tomas ilegales descubiertas en la red de combustible de México casi se quintuplicara (Stargardter, 2018). Los Zetas y Los Templarios han incursionado en el robo de mineral pero también en su exportación, como en el caso del hierro que envían desde el puerto de Lázaro Cárdenas hacia China. ${ }^{12}$

El otro elemento que debe ser referido sobre las nuevas características de los grandes grupos de traficantes de droga es el de su perfil militar, el cual comenzó a tomar forma con Los Zetas (grupo gestado por Osiel Cárdenas Guillén, en el Cártel del Golfo), pero se ha extendido a múltiples grupos delictivos de ese calado. De acuerdo con Carlos Flores, los motivos para que los grandes traficantes de droga se perfilen como paramilitares son "El debilitamiento de los controles para frenar a la delincuencia organizada; la transferencia de militares a instituciones corruptas para enfrentar al narco; la corrupción en diversos organismos y la esfera política" (Flores, 2014), lo que se conjuga con la diversificación de la actividad delictiva.

\section{PERFIL TRANSNACIONAL}

El perfil trasnacional de las RTC parte del engarce de su capital criminal con capitales financieros radicados en otras latitudes, y el rol que toman en la planeación y perpetración de delitos en diversos países. Ello ajusta con las consideraciones que María del Pilar Fuerte Celis hace con base en la literatura de Letizia Paoli, Tom Vander Beken y Jean François Gayraud, sobre el punto de que el carácter transnacional se relaciona con la globalización económica; los delitos cometidos en un país, pero planificados en otros, y los delitos cometidos en un territorio administrativo, pero con la participación de un grupo criminal que interviene en más de un país (Fuerte, 2016, p. 13).

El negocio del tráfico de drogas ilícitas en el que los criminales mexicanos incursionaron desde el siglo $\mathrm{xx}$ nació transnacionalizado, en particular

${ }^{12}$ L. Hernández, "Minería, narco y comunidades indígenas", La Jornada, 9 de mayo de 2017. Recuperado de https://www.jornada.com.mx/2017/05/09/opinion/017a2pol 
para satisfacer la demanda que comenzó a tomar forma desde Estados Unidos. ${ }^{13}$ Cabe señalar en este punto que es desde la propia dimensión transnacional que también se alienta la violencia que se padece en México, en tanto el conflicto es alimentado por actividades ilegales de naturaleza transnacional, como son las drogas traficadas en y a través de México que buscan llegar al mercado estadunidense, así como por el tráfico de armas (Rodríguez, 2016, pp. 52, 53).

En la actualidad la expansión de las RTC ha alcanzado niveles más elevados, y la posición tradicional de México como territorio de tránsito -principalmente- en la cadena de valor de la droga que incluye países productores, de paso y de consumo se ha mantenido, pero también ha pasado a ser el de albergar a varias Redes Transnacionales de Criminalidad que operan de distintas formas y en diversos giros delictivos en múltiples latitudes del orbe. El llamado Cártel de Sinaloa sigue siendo la RTC mexicana con mayor alcance a escala transnacional y, a pesar de la detención de Joaquín Guzmán Loera, ello no ha hecho mella en ese grupo criminal. Cabe señalar que desde 2012 se estimó que esa RTC tenía presencia en más de 50 países (Verza, 2012), y ello no se modificó para 2018, de acuerdo con el Servicio Legislativo de Investigación del Congreso estadunidense (Redacción El Universal, 2018), lo que da cuenta de la capacidad de continuidad y reemplazo de miembros (Fuerte, 2016, p. 14), así como de que las RTC no se desmoronen a pesar de la detención de alguno de sus líderes.

Según la agencia antinarcóticos estadunidense, las RTC mexicanas que tienen mayor presencia en el exterior son el Cártel de Sinaloa, Los Zetas, Cártel Jalisco Nueva Generación, Familia Michoacana, Cártel del Golfo, Cártel de Tijuana, Caballeros Templarios, Cártel de Juárez (Redacción Infobae, 2017). Además de su presencia en los cinco continentes, abastecen al mercado de las drogas más demandante del planeta, el estadunidense, y entre 2013 y 2017 habrían lavado hasta 3 billones 646500 millones de pesos (a razón de entre 6000 millones y 39000 millones de dólares anuales, según el Departamento del Tesoro estadunidense) sólo por el negocio de las drogas ilícitas en dicho mercado (Flores, 2018). A estos montos habría que agregar sus ganancias por los delitos a nivel México señalados párrafos arriba, así como una maraña de negocios lícitos en los que incursionan para lavar la ganancia espuria. El

${ }^{13}$ Drogas como la mariguana, la metanfetamina y la heroína producidas en México han tenido como pivote de consumo Estados Unidos, pero la cocaína sí se ha exportado hacia otros lugares, como Canadá (Resa-Nestares, 2003, p. 24). 
tinglado corporativo en el que se viabiliza con éxito la relación capitales lícitos e ilícitos de las RTC es similar al empleado por las multinacionales, en tanto que buscan "administrar sus cadenas de suministro, cuidar sus recursos humanos, invertir en investigación y desarrollo, explorar el comercio minorista en línea y dedicar mucho tiempo y dinero al marketing. Incluso se pasan una cierta cantidad de tiempo preocupándose por la responsabilidad social corporativa" (Villalba, 2018) con la intención de cimentar buenas relaciones con las comunidades locales, lo que es congruente con su tradición en México de buscar proyectarse como "agentes benefactores".

A la par del lavado de dinero cuentan con diversos métodos para blanquear fondos, como la compra de artículos de venta al por menor en Estados Unidos para exportar y revender en México; intercambio de criptomonedas, contrabando de efectivo a granel y el uso de cuentas embudo, con las que se estructuran depósitos de baja denominación en varias cuentas abiertas en instituciones financieras de Estados Unidos para ser canalizados a una cuenta centralizada en México (Flores, 2018). El lavado de dinero es un fenómeno que vincula a las RTC y al sistema bancario. HSBC se hizo merecedor en 2012 de una multa por 1920 millones de dólares, debido a que permitió, en cerca de una década, a dos grandes grupos de traficantes de droga -uno mexicano y otro colombiano- ingresar al sistema financiero 881000000 de dólares. Pese al fuerte monto con el que fue penalizado, ello no evitó por completo que otros bancos recibieran dinero proveniente de fuentes ilícitas. Rabobank, por ejemplo, en 2018 fue multado con 368700000 dólares porque su "deficiente programa" contra lavado de activos permitió la inversión de cientos de millones de dólares imposibles de rastrear, de acuerdo con lo dado a conocer por el Departamento de Justicia de Estados Unidos, ello a pesar de que desde 2010 se endurecieron las leyes contra lavado de dinero. En el vínculo bancos-RTC, y en particular para el caso de México, la complicidad ha estado considerablemente extendida. BBVA-Bancomer y Santander, de origen español; el estadunidense Citibanamex; el británico HSBC; el canadiense Scotiabank, y los mexicanos Banorte e Inbursa, así como casas de bolsa, de cambio y entidades de la banca múltiple comercial, figuran entre los sectores clasificados de más alto riesgo o más expuestos al lavado de dinero y financiamiento al terrorismo, según la Unidad de Inteligencia Financiera (UIF) (Flores, 2016).

Estos agentes que participan del lavado de dinero contribuyen a la valorización del capital criminal que también conjuga la cadena de valor de la droga y negocios paralelos, y forman parte de las redes que se tienden entre 
varios países y actúan al amparo de la desregulación del sistema financiero. $\mathrm{Su}$ actividad se relaciona con la dimensión transnacional por la proyección y engarces que las RTC han realizado, y con la dimensión de redes por la forma en que operan y articulan sus redes corporativas. Pero también con la criminal en tanto el lavado de dinero se considera "todo acto o intento de ocultar o encubrir el origen de ingresos obtenidos ilegalmente para hacer parecer que provienen de fuentes legítimas" (Buscaglia, 2015, p. 42).

Para los traficantes de droga, opciones para ingresar el dinero en el sistema bancario son comprar negocios legales y utilizar sus cuentas bancarias para lavar dinero; el uso de testaferros sin historial delictivo para lavar sus recursos; diseñar operaciones financieras complejas apoyándose en los especialistas financieros a su servicio. No obstante, uno de los mayores aspectos a su favor es el de que en México no hay un estudio serio sobre cómo funciona el lavado de dinero, lo que se refleja en la muy baja cantidad de acciones penales y condenas por casos de lavado de activos (Nájar, 2018). Pese a las brutales ganancias que reciben las RTC, lo cierto es que no representan el eslabón privilegiado en la cadena que comprende el ciclo de producción, traslado y lavado de dinero. Los paraísos fiscales, por ejemplo, no son objeto de un escrutinio tan fuerte como sí lo son las RTC, y la "guerra contra las drogas" comandada por Estados Unidos minimiza sistemáticamente la responsabilidad de los países centrales, tanto como pivote de la demanda de las drogas ilícitas, como por el masivo blanqueo de capitales que se hace dentro de sus fronteras. Es decir, la criminalización, de facto, está orientada hacia los países de producción y tránsito de estupefacientes, primordialmente los que pueden considerarse periféricos.

Se trata de un fenómeno paralelo a la inequitativa división del trabajo que existe al interior de las actividades del narcotráfico, sólo que, en lugar de la desigualdad existente entre cultivadores de droga y grandes capos, se da entre los grupos de traficantes de estupefacientes y los bancos que participan de la cadena de valor de la droga, y en una escala mayor, entre países periféricos y centrales. Los motivos de lo anterior descansan en una política geoestratégica y en una impunidad de gran calado, y no en la simple maximización de ganancia a partir de bajos salarios o el incremento de los riesgos, como ocurre en la división del trabajo al interior de las actividades del narco. La narrativa del narco lo encumbra y proyecta a través de múltiples formas de entretenimiento, así como por diversos medios de comunicación que encuentran en este un tema que potencia la venta de diarios e incrementa los ratings, pero lo cierto 
es que en términos reales esa visibilización representa un "talón de Aquiles" que en el esquema punitivo-prohibicionista es por demás perjudicial para los grupos criminales, pues por una parte se convierten en objetivos prioritarios para las autoridades, y por el otro encarnan el agente que la ciudadanía identifica como el centro del problema del tráfico de estupefacientes.

Ahora bien, la discrecionalidad que en el sistema financiero cobija el lavado de dinero proveniente del tráfico de estupefacientes apunta a que también puede ser una fórmula efectiva para blanquear ganancias de otros ilícitos ejercidos por las RTC, como la trata de personas. Es decir, los grupos criminales estarían aprovechando el andamiaje financiero y de rutas para desarrollar nuevos ilícitos, y las redes comenzarían a tejerse a nivel nacional, como refleja el Diagnóstico Nacional sobre la Situación de la Trata de Personas en México, el cual advierte que habría al menos tres niveles en esa maraña: redes de familiares, vecinos o parientes que viven cerca de la víctima y venden, rentan o prestan a sus hijos para conseguir dinero; un segundo nivel son grupos locales, miembros de pequeños grupos de delincuentes y criminales que operan individualmente, y en última instancia los grandes "Grupos de Delincuencia Organizada" (Andrade, 2016). El nicho de ganancia no es nada despreciable para las RTC, pues como se desprende del "Diagnóstico de las Condiciones de vulnerabilidad que propician la Trata de Personas en México”, elaborado por la Comisión Nacional de los Derechos Humanos y el Centro de Estudios e Investigación en Desarrollo y Asistencia Social, la trata de personas representa el segundo ilícito más redituable para esos grupos delictivos (Guillén, 2011), lo cual es congruente con las estimaciones de la Organización para la Cooperación y el Desarrollo Económico (OCDE), organismo que afirma que la trata de personas es el segundo negocio ilícito más redituable a nivel mundial para el llamado crimen organizado, y anualmente le deja cerca de 32000 millones de dólares (Hernández, 2014).

El punto crítico sobre el que hay que hacer hincapié en este tema es que a diferencia del trasiego de estupefacientes, la trata de personas corresponde a los delitos que atentan contra la vida digna y por tanto el desarrollo humano, y la participación de los bancos en ese entramado da cuenta de que una de las facetas más lacerantes del capital criminal, como es la trata de personas, ${ }^{14}$

${ }^{14}$ Además de la trata de personas, se pueden agregar como delitos que atentan contra la vida el trabajo forzado, el despojo violento, el homicidio, la trata de personas, la explotación laboral, el robo, la extorsión o el secuestro, los cuales son ejercidos por las RTC. 
no es incompatible con el capital financiero que busca maximizar ganancias a costa de lo que sea, incluso la vida misma o la integridad de las personas.

\section{CONCLUSIONES}

Definir a los grandes grupos de traficantes de droga como Redes Transnacionales de Criminalidad marca una diferencia con los conceptos de crimen organizado, cárteles y narcotráfico que abarca siete puntos.

1. A diferencia del crimen organizado, las RTC no están planteadas bajo el esquema punitivo-prohibicionista de la noción dominante en materia de seguridad, ni promueven la criminalización que en el marco de la dinámica centro-periferia se acentúa sobre países productores en la cadena de valor de la droga. Por el contrario, el concepto se propone como marco para analizar cómo esto último ha resultado funcional para la estimulación de los mercados ilegales y la criminalización focalizada.

2. Más allá del umbral numérico que parte de tres o más miembros en el concepto de crimen organizado, lo que se visibiliza desde las RTC es la rotación de elementos, así como la tendencia a la suma de individuos por su necesidad de ampliar su fuerza laboral y paramilitar a partir de la ramificación de sus delitos, la ofensiva desatada con la guerra contra el narco, y el propio refuerzo armado de grupos criminales antagónicos.

3. En contraparte a la idea de que la organización del crimen organizado es piramidal, la característica red da cuenta del proceso de descentralización y la lógica operativa a la que han transitado esos grupos criminales. Esta última da cobijo tanto al negocio del tráfico de estupefacientes como a los nuevos ilícitos sobre los que se han volcado, incluidos los que atentan contra la vida y por tanto el desarrollo humano.

4. A diferencia de la noción de cárteles que desde los preceptos económicos ubican a los grupos criminales en la posición del monopolio, las RTC los identifican como agentes en disputa ( sin soslayar los casos de alianza) y franco proceso de fragmentación -en particular en el presente contexto mexicano-, lo que permite no simplificar el fenómeno de criminalidad vigente, y contribuye a superar los desvíos semánticos y el abuso del término que se genera en los medios de comunicación.

5. El componente de criminalidad de las RTC no busca acotar los ilícitos en los que participan a la órbita del trasiego de estupefacientes que, por 
definición, se corresponde con el narcotráfico, sino abrir la posibilidad de dimensionar el amplio abanico de delitos en los que han incursionado en los últimos años para la maximización de ganancia.

6. El componente transnacional del concepto implica superar-sin descartarla- la noción de la lógica oferta-demanda entre países productores y consumidores de droga. A lo que se apunta es a visibilizar el tinglado criminal de las RTC que soporta delitos como la trata de personas, de órganos, de nuevos estupefacientes, entre otros que buscan satisfacer mercados nacientes, así como a dar cuenta del engarce entre el capital criminal y el sistema financiero que interviene en su valorización.

7. El concepto de RTC parte de una base teórica derivada de estudios sobre el Estado; estudios críticos a la posición dominante en materia de seguridad y estudios ocupados del tema criminológico -entendido como una subespecialidad de la sociología- que toman distancia de las visiones garantistas y reduccionistas. El mirador teórico construido marca diferencias con los conceptos de crimen organizado, narcotráfico y cárteles, pero también propicia la disertación sobre el tipo de evolución de los grupos criminales, su rol en fenómenos como el intervencionismo y la vinculación del capital criminal en el sistema capitalista global.

Contar con un concepto como el de las RTC para abarcar el amplio espectro de actividades y desarrollo que presentan esos grupos criminales, posibilita una mejor comprensión de los mismos y permite reducir desaciertos en términos de definición. Los grados de autonomía y atomización que han alcanzado, sus reconfiguraciones organizativas, el cambio en sus relaciones con el Estado, su proyección hacia el exterior, así como su perfil militar y la ramificación de los delitos en los que incurren, ajustan con la definición de Redes Transnacionales de Criminalidad. Esta serie de nuevos rasgos de los grupos criminales representa un giro significativo para los estudios sobre la temática criminal, pero también permiten comprender fenómenos ligados, particularmente en las dimensiones económica, política y social. En ese sentido, hay que destacar el engarce de las RTC con el sistema financiero, el cual es clave para dar continuidad a la cadena de valor de la droga, así como a las cadenas de valor de los delitos paralelos en los que incurren, incluidos los que atentan contra la vida digna. Un elemento representativo de dicha relación son los grados de impunidad que tienen las RTC y el sistema financiero, el cual es inequitativo -en tanto se enfoca principalmente en la criminalización de las primeras-, pero congruente con los privilegios que tienen los agentes 
radicados o que son cobijados por las políticas de los países centrales. Capitales lícitos e ilícitos son mezclados en el sistema financiero y los paraísos fiscales de forma indiscriminada y cada vez más corrupta, pues dicho sistema ha dado muestras de tener apertura a los ingresos producto de los delitos que atentan contra la vida y por tanto el desarrollo humano.

Las condiciones de vulnerabilidad social que México padece en la actualidad resultan un fermento idóneo para las RTC, ello a partir del nexo que se genera entre las violencias sistémicas (exclusión social, falta de oportunidades educativas, precarización del empleo), y la violencia emergente que desatan las RTC en contra de la población (asesinato, despojo, uso obligado de la fuerza de trabajo). El fenómeno en sí no es nuevo, y hay relativo consenso sobre la facilidad de la que gozan los grupos criminales para poder aprovecharse de grupos vulnerables, pero lo que sí es más reciente es el grado de cooptación de las RTC sobre esos grupos, su cobertura en nuevas áreas del país y el extranjero -particularmente al sur de la frontera mexicana-, el tipo de explotación que ejercen y los nuevos grupos sociales que reclutan u obligan a engrosar su excedente. Se trata de una espiral de violencias que se alimenta a sí misma en el marco del modelo de desarrollo neoliberal mexicano, el cual funge como la fuente que supura violencias sistémicas. La violencia de Estado que se despliega para presuntamente acotar la violencia criminal ha encontrado uno de sus más grandes desaciertos en el esquema punitivo en el que se apoya, pues a partir de la deficiente procuración de justicia que ya existía en el país previo al inicio de la guerra contra el narcotráfico, no sólo no se ha limitado efectivamente a las RTC, sino que han aumentado las víctimas mortales y se ha encarcelado a miles de inocentes.

Es importante mencionar que para México dicho esquema punitivo encuentra su mayor influencia en los preceptos en materia de seguridad estadunidenses orientados a las medidas reactivas y punitivas (lo que se refleja en los Planes Nacionales de Desarrollo de los últimos tres sexenios panistas y priista), en particular en los que se derivan de su "guerra contra las drogas", y que dicho esquema no es equitativo en tanto criminaliza al sur con respecto al norte global y termina por ser un refuerzo del establishment estadunidense. La gran contrariedad de minimizar la responsabilidad de determinados países (en particular Estados Unidos) en el gran consumo de estupefacientes es congruente con la posición de privilegios de las naciones centrales, y el prohibicionismo que desde ellas mismas se promueve implica que los mercados ilícitos sigan vigentes e incluso se generen nuevos. Obtener datos precisos 
sobre las cifras de ganancia, volúmenes de producción o dimensiones de lo exportado por parte de las RTC es complicado, incluso para los grandes organismos enfocados en la materia; no obstante, es posible notar las tendencias de las RTC hacia nuevos mercados, la presencia que tienen en determinadas regiones, y como se ha hecho en este texto, es posible discernir fenómenos paralelos a la evolución de las RTC y la relación que guardan con estos.

En ese sentido se hace evidente que las medidas punitivas y orientadas a confrontar a las RTC como si estuvieran organizadas de forma piramidal son inadecuadas, y guardan congruencia con la necesidad de los gobiernos de presumir resultados en la detención de grandes capos, por lo que resultan cortoplacistas y de escaso efecto para vulnerar las fortalezas de las RTC. En todo caso las autoridades mexicanas quedan relativamente rebasadas para poder frenar en lo sustancial a las RTC, en particular si se considera que su fuerza radica en gran medida en las redes que han extendido hacia el exterior, en la ramificación de delitos que bien pueden amortiguar un eventual acotamiento de su ingreso por trasiego de droga, y en una "lucha" de parte de los países interesados que es permanente pero no termina por ser firme contra dos elementos neurálgicos del fenómeno: la demanda de droga que desde los países centrales sigue estable, y el sector financiero que recibe las ganancias de las RTC. Irónicamente, las Redes Transnacionales de Criminalidad terminarían por beneficiarse de dichas omisiones, y ello les representa una garantía muy fuerte para seguir activas e incluso proyectarse con mayor fuerza.

\section{LISTA DE REFERENCIAS}

Andrade, M. (1 de mayo, 2016). Bandas de trata de personas y cárteles: una relación cercana en México. Vice. Recuperado de https://www.vice.com/es_latam/article/ $\mathrm{kzjed}$ /trata-de-personas-y-carteles-relacion-cercana-en-mexico

Argueta, O. (2014). Las bisagras del crimen organizado y la política en el Triángulo Norte Centroamericano. Seminario Internacional Violencia Armada, Crimen Organizado y Política en América Latina, Instituto de Investigaciones Sociales-Universidad Nacional Autónoma de México.

Astorga, L. (2012). El siglo de las drogas. México: Grijalbo-Proceso.

Astorga, L. (2014). Delincuencia organizada y cambio político en México. Seminario Internacional Violencia Armada, Crimen Organizado y Política en América Latina, Instituto de Investigaciones Sociales-Universidad Nacional Autónoma de México. 
Astorga, L. (2015). Drogas sin fronteras. México: Debolsillo.

Azaola, E. y Bergman, M. (2003). El sistema penitenciario mexicano. UC San Diego: Center for U.S. - Mexican Studies. Recuperado de: https://escholarship.org/uc/ item/18w2r3h7\#author

Bailey, J. y Taylor, M. (2009). Evade, corrupt, or confront? Organized crime and the state in Brasil and Mexico, Journal of Politics in Latin America, 1(2), 3-29.

Benito, M. (2015). Estados Unidos y América Latina: una relación construida desde el poder y la inseguridad. En J. Sierra, M. Benito y A. Castillo (coords.), La arquitectura de la violencia y la inseguridad en América Latina. Madrid: Ed. Catarata.

Buscaglia, E. (2013). Vacíos de poder en México. México: Debate.

Buscaglia, E. (2015). Lavado de dinero y corrupción política. México: Debate.

Calveiro, P. (2012). Violencias de Estado. México: Siglo XXI Editores.

Camacho, Z. (2 de junio, 2013). Los 89 cárteles que arrasan México. Contralínea. Recuperado de https://www.contralinea.com.mx/archivo-revista/2013/06/02/ los-89-carteles-arrasan-mexico/

Castillo, A., Ríos, J. y Peccis, Á. (2015). Panorama de la seguridad en América Latina. En J. Sierra, M. Benito y A. Castillo (coords.), La arquitectura de la violencia y la inseguridad en América Latina. Madrid: Ed. Catarata.

Chabat, J. (2010). La respuesta del gobierno de Calderón al desafío del narcotráfico, entre lo malo y lo peor. En A. Alvarado y M. Serrano, Seguridad nacional y seguridad interior. México: El Colegio de México.

Contreras, R. (2013). How government structure encourages criminal violence: the causes of Mexico's drug war. (Tesis de doctorado). Harvard University.

Contreras, M. (2012). Marco jurídico de la delincuencia organizada en México. México: Dirección General Editorial de la Universidad Veracruzana.

Corte Ibáñez, L. de la y Giménez-Salinas, A. (2010). Crimen.org. México: Ariel.

Duncan, G. (2014). Más que plata o plomo. El poder político del narcotráfico en Colombia y México. Bogotá: Debate.

EFE (2014). Los cárteles mexicanos, con "bolsa de trabajo" propia. Infobae. Recuperado de https://www.infobae.com/2014/05/26/1567655-los-carteles-mexicanos-bolsa-trabajo-propia/

Emerich, N. (2015). Geopolítica del narcotráfico en América Latina, México: Instituto de Administración Pública del Estado de México.

Escribano, J. (2009). Terrorismo, narcotráfico, blanqueo de capitales, trata de personas, tráfico ilícito de migrantes, tráfico ilícito de armas: lucha global contra la delincuencia organizada internacional. Madrid: Visión Libros. 
Finckenauer, J. (2005). Problems of definition: What is organized crime. Trends in Organized Crime, 8(3), 63-83.

Flores, C. (2014). Inicia el horror. Los orígenes de la delincuencia organizada paramilitar en México. Seminario Internacional Violencia Armada, Crimen Organizado y Política en América Latina, Instituto de Investigaciones Sociales-Universidad Nacional Autónoma de México.

Flores, N. (23 de octubre, 2016). Bancos han lavado más de 150 mil millones de pesos. Contralínea. Recuperado de https://www.contralinea.com.mx/archivo-revista/2016/10/23/bancos-han-lavado-mas-de-150-mil-millones-de-pesos/

Flores, N. (28 de marzo, 2018). 3.6 billones de pesos, ganancias del narcotráfico mexicano. Contralínea. Recuperado de https://www.contralinea.com.mx/archivo-revista/2018/03/28/3-6-billones-de-pesos-ganancias-del-narcotrafico-mexicano/

Fuerte, M. (2016). Geografía de la violencia en México. Un acercamiento a la reconfiguración territorial de la violencia generada por el crimen organizado. México: Centro de Investigación y Docencia Económicas.

Garay, J. y Salcedo, E. (2012). Narcotráfico, corrupción y Estados. México: Debate. González, M. (2014). Narcotráfico y crimen organizado, Barcelona, Icaria.

Grayson, G. (2017). Mexico: Narco-violence and a failed State? Nueva York: Routledge. Guillén, P. (13 de abril, 2011). Trata de personas, segundo ilícito más redituable en México. Animal Político. Recuperado de https://www.animalpolitico.com/2011/04/ trata-de-personas-segundo-ilicito-mas-redituable-en-mexico/

Hernández, A. (2010). Legislación de drogas y situación carcelaria en México. En P. Metaal y C. Youngers (eds.), Sistemas sobrecargados, leyes de drogas y cárceles en América Latina. Amsterdam/Washington: Wola/TNI. Recuperado de: https://www. wola.org/sites/default/files/downloadable/Drug\%20Policy/2011/Spanish/sistemas_sobrecargados_web2.pdf

Hernández, E. (2014). Deja la "trata de personas" ganancias por 32 mil mdd al año, revela la ocDE. Organización Editorial Mexicana. Recuperado de http://www.oem. com.mx/laprensa/notas/n3309265.htm

Justo, M. (31 de marzo, 2016). Las cinco actividades del crimen organizado que recaudan más dinero en el mundo. BBC News Mundo. Recuperado de https://www.bbc. com/mundo/noticias/2016/03/160316_economia_crimen_organizado_mj

López de Rivera Hinojosa, L. N. (25 de julio, 2018). Aumenta guerra narco capitalina; 11 cárteles operan en la CDMx. Televisa.NEWS. Recuperado de https://noticieros. televisa.com/ultimas-noticias/aumenta-guerra-narco-capitalina-11-carteles-operan-cdmx/ 
Mayorga, P. (5 de abril, 2020). Rarámuris denuncian tala de árboles ilegal durante emergencia por covid-19. Proceso. Recuperado de https://www.proceso.com.mx/ nacional/estados/2020/4/5/raramuris-denuncian-tala-de-arboles-ilegal-durante-emergencia-por-covid-19-240917.html

Montemayor, C. (2010). La violencia de Estado en México. Antes y después de 1968. México: Debate.

Nájar, A. (9 de febrero, 2018). Por qué es tan fácil para el narco en México hacer negocios con los bancos (y por qué es tan difícil combatirlo). BBC News Mundo. Recuperado de https://www.bbc.com/mundo/noticias-america-latina-42998699

Osorio, J. (2011). Crisis estatal y violencia desnuda: la excepcionalidad mexicana. En J. Osorio, Violencia y crisis del Estado. México: Universidad Autónoma Metropolitana.

Ravelo, R. (24 de septiembre, 2018). El 80\% de los alcaldes están vinculados al narco y hay 15 cárteles en expansión, admite Senado. Sinembargo. Recuperado de https:// www.economiahoy.mx/nacional-eAm-mx/noticias/9406898/09/18/El-80-de-losalcaldes-estan-vinculados-al-narco-y-hay-15-carteles-en-expansion-admite-Sena do.html

Real Academia Española (2019). Real Academia Española. Recuperado de http://www. rae.es

Redacción Animal Político (28 de marzo, 2017). Narco y su relación con la política, lo que reveló Miroslava Breach antes de ser asesinada. Animal Político. Recuperado de https://www.animalpolitico.com/2017/03/miroslava-breach-narcotrafico/

Redacción Aristegui Noticias (16 de septiembre, 2014). Hay 9 cárteles del narco en México; controlan 43 pandillas: PGR. Aristegui Noticias. Recuperado de https:// aristeguinoticias.com/1609/mexico/hay-9-carteles-del-narco-en-mexico-contro lan-43-pandillas-pgr/

Redacción El País (10 de mayo, 2016). El narcotráfico se infiltra en la contienda electoral en Tamaulipas. El País. Recuperado de https://elpais.com/internacional/2016/05/09/mexico/1462751826_825956.html

Redacción El Universal (12 de junio, 2018). Cárteles mexicanos, con presencia en 50 países. El Universal. Recuperado de https://www.eluniversal.com.mx/nacion/seguridad/carteles-mexicanos-con-presencia-en-50-paises

Redacción Infobae (12 de noviembre, 2017). Cuáles son los cárteles mexicanos que dominan el mercado mundial de la droga y en qué países operan. Infobae. Recuperado de https://www.infobae.com/america/mexico/2017/11/12/cuales-sonlos-carteles-mexicanos-que-dominan-el-mercado-mundial-de-la-droga-y-en-quepaises-operan/ 
Redacción Expansión (27 de octubre, 2019). Impunidad en guerra contra el narco; de 233, solo dos con sentencia irrevocable. Expansión. Recuperado de: https:// politica.expansion.mx/mexico/2019/10/27/impunidad-en-guerra-contra-el-narco-de-233-solo-dos-con-sentencia-irrevocable

Redacción Sinembargo (16 de abril, 2014). Los cárteles depredan selvas y bosques desde el sur de México y hasta Centroamérica, alertan investigadores. Sinembargo. Recuperado de https://www.sinembargo.mx/16-04-2014/963667

Resa-Nestares, C. (2003). El valor de las exportaciones mexicanas de drogas ilegales, 1961-2000. Madrid: Universidad Autónoma de Madrid-Departamento de Estructura Económica y Economía del Desarrollo-Facultad de Ciencias Económicas y Empresariales.

Rodríguez, F. (2016). Violent Mexico: Participatory and multipolar violence associated with organised crime. International Journal of Conflict and Violence, 10(1), 44-60.

Roux, R. (2011). Ausencia de ley, el desmoronamiento del Estado mexicano. En J. Osorio, Violencia y crisis del Estado. México: Universidad Autónoma Metropolitana.

Stargardter, G. (24 de enero, 2018). Violentos cárteles de droga paralizan refinerías de México con robo de combustible. Reuters. Recuperado de https://www.reuters. com/article/delito-mexico-combustible-idLTAKBN1FD1KA-OUSLB

Trelles, A. y Carreras, M. (2012). Bullets and votes: violence and electoral participation in Mexico. Journal of Politics in Latin America, 4(2), 89-123.

UNODC (2019). Crimen organizado transnacional. UNODC. Recuperado de https:// www.unodc.org/ropan/es/organized-crime.html

Naciones Unidas (26 de junio, 2012). onU presenta informe sobre drogas de 2012. Noticias ONU. Recuperado de https://news.un.org/es/story/2012/06/1245711

Verza, M. (12 de agosto, 2012). El cártel de Sinaloa, una multinacional de las drogas. ElMundo.es Recuperado de https://www.elmundo.es/america/2012/08/11/mexico/1344653365.html

Villafañe, V. (2015). Crimen perfecto. El manual de la impunidad en México. Observatorio del Desarrollo, 4(14), 5-13.

Villalba, J. (22 de febrero, 2018). Por qué los cárteles de la droga tienen franquicias igual que McDonald's. Vice. Recuperado de https://www.vice.com/es/article/3k7555/carteles-droga-funcionan-como-multinacionales.

Von Lampe (2016). Organized crime. Analyzing illegal activities, criminal structures, and extra-legal governance. Estados Unidos de América: SAGE.

Wacquant, L. (2004). Las cárceles de la miseria. Buenos Aires: Manantial. 